\title{
Guidelines
}

\section{Intradiscal Electrothermal Therapy (IDET) for the Treatment of Discogenic Low Back Pain: Patient Selection and Indications for Use}

David S. Kloth, MD', Douglas S. Fenton, $\mathrm{MD}^{2}$, Gunnar B.J. Andersson, MD, $\mathrm{PhD}^{3}$, and Jon E. Block, PhD ${ }^{4}$

From: ${ }^{1}$ Connecticut Pain Care, Danbury, CT; ${ }^{2}$ Department of Radiology, Mayo Clinic, Jacksonville, FL; ${ }^{3}$ Department of Orthopedic Surgery, Rush University Medical Center, Chicago, IL; ${ }^{4}$ Jon E. Block, PhD, Inc., San Francisco, CA.

Dr. Kloth is Medical Director of Connecticut Pain Care, Danbury, CT. Dr. Fenton is Assistant Professor of Radiology, Mayo Medical School, Jacksonville, FL. Dr. Andersson is Professor and Chairman Emeritus, The Ronald L. Dewald, MD, Chair in Spinal Deformities, Rush University Medical Center, Chicago, IL. Dr. Block is President, Jon E. Block, PhD, Inc.

Address correspondence: Jon E. Block, PhD 2210 Jackson Street, \#401 San Francisco, CA 94115 E-mail: jonblock@jonblockphd.com

Disclaimer: This communication was supported, in part, by Smith \& Nephew (Memphis, TN).

Conflict of interest: None.

Manuscript received: $04 / 18 / 2008$ Revised manuscript received: 07/03/2008

Accepted for publication: 07/07/2008

Free full manuscript: www.painphysicianjournal.com
Discogenic low back pain resulting from internal disc disruption can be severely disabling, clinically challenging, and expensive to treat. Previously, when conservative care had been exhausted, open surgical intervention such as spinal fusion or artificial disc replacement was the only treatment option for these patients. Intradiscal electrothermal therapy (IDET), a minimally-invasive technique performed in the outpatient setting, offers an intermediate intervention between conservative care and surgery. Specific selection criteria have been refined that identify patients for treatment with IDET, ensuring maximal clinical benefit and appropriate use of healthcare resources.

Indications for use were developed from review of selection criteria from published clinical reports and review articles of IDET, and further refined by identifying components with the strongest positive predictive value and by direct physician feedback. Final indications for use consist of clinical and imaging criteria.

There are 5 compulsory indications for use: 1) persistent axial low back pain +/- leg pain and non-responsive to $\geq 6$ weeks of conservative care; 2 ) history consistent with discogenic low back pain without marked lower extremity neurological deficit; 3 ) one to 3 desiccated discs with or without small, contained herniated nucleus pulposus by T2-weighted magnetic resonance imaging, with at least 50\% remaining disc height; 4) concordant pain provocation by low pressure ( $<50$ psi above opening pressure) discography; and, 5) posterior annular disruption by post-discography computed tomography. Using these patient selection characteristics, approximately 3 of 4 IDETtreated patients should achieve a minimal clinically important improvement in pain and disability.

Key words: intradiscal electrothermal therapy, IDET, annuloplasty, back pain, disc disruption

Pain Physician 2008; 11:5:659-668

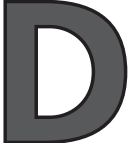
egeneration of the intervertebral disc is a nearly universal phenomenon with aging that is asymptomatic in most individuals (1-3). However, pathologic deterioration of the intervertebral disc, termed internal disc disruption, can be a major cause of pain and disability leading to diminished quality of life for many (4-6).
Imaging findings of disc disease often include decreased disc signal and evidence of a high-intensity zone on T2-weighted magnetic resonance images representing posterior annular tears, fissuring, ruptures, and/or delamination, as well as subchondral changes, disc space narrowing or collapse, which can ultimately result in intractable low back pain (7-10). 
Repetitive mechanical loading of degenerated and disrupted outer annular fibers leads to a vicious cycle of persistent inflammation, matrix damage, and sensitization of developed annular nociceptors (11-13). Histological studies suggest that in response to disc degeneration and lamellar disruption, neovascularization, neuronal penetration with unmyelinated nerve fibers, and ingrowth of Schwann cells occur $(1,14-16)$.

Radial annular fissures allow nucleus pulposus matrix substance to migrate to the outer annulus and induce nerve in-growth into delaminated regions (17). Biochemical evidence appears to indicate that painful discs are the result of repetitive injury and subsequent repair mechanisms leading to vascularized granulation tissue along torn annular fissures $(6,13)$. Mast cell proliferation and release of inflammatory mediators along zones of granulation tissue sensitize damaged annular regions to mechanical and chemical stimuli $(7$, 15,18-21). It has been observed that at least a portion of the neoinnervation that is associated with this process provides a sensory function, potentially acting as a pain generator $(15,16,22)$.

Clearly disc degeneration is not a benign event. It has been estimated that internal disc disruption is associated directly with chronic pain in approximately $40 \%$ of patients reporting persistent symptoms of unknown origin $(23,24)$. Most patients with definitive imaging evidence of degenerated discs or internal disruption and severe back symptoms that persist beyond 3 months do not have a good prognosis for recovery with conservative management alone (25-27). This fact cannot be ignored and these patients are often confronted with the dilemma of living with persistent pain, behavioral modifications, possible analgesic dependency, or surgery (28-30).

\section{Minimally Invasive Treatment of Internal Disc DisRuption}

Discogenic pain is distinct from disc herniation with radiculopathy, for which surgical treatment is usually disc decompression (31). If surgical treatment is used, presumed discogenic pain is typically treated with spinal fusion, and more recently with total artificial disc replacement. However, a minimally invasive technique, known as annuloplasty, offers an intermediate intervention between conservative care and more invasive surgical procedures (29). Annuloplasty refers to several percutaneous methods that provide presumptive clinical benefit via direct heating of the annulus. One technique,

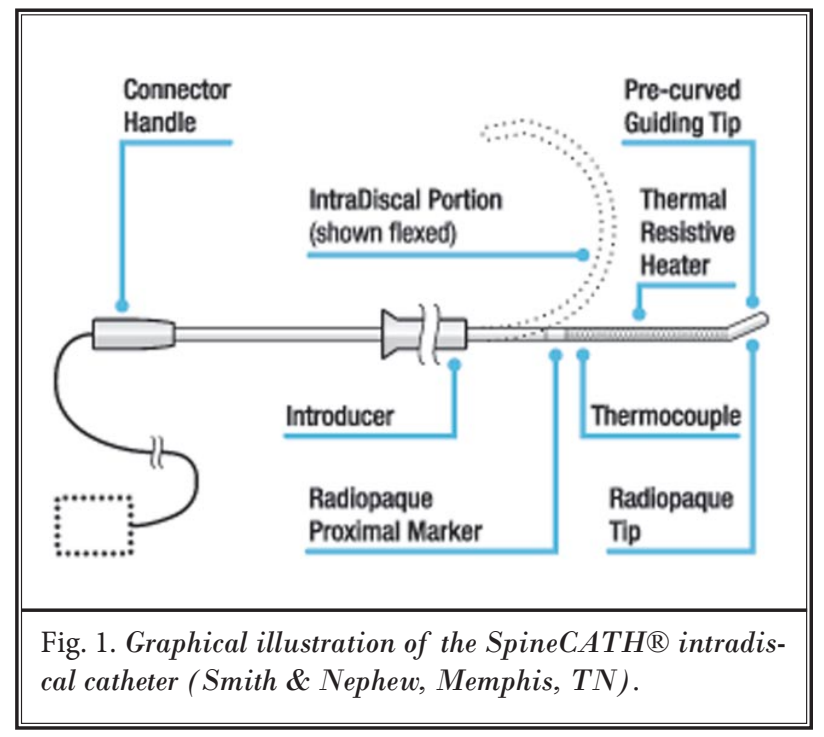

intradiscal electrothermal therapy (IDET), has been the most widely studied annuloplasty method, and is the subject of this report (32).

Percutaneous IDET is a minimally invasive technique, which uses a navigable intradiscal catheter (SpineCATH ${ }^{\circ}$, Smith \& Nephew, Memphis, TN) (Fig.1) that is radiologically guided into the outer posterior or posterolateral annulus across a previously identified tear (Fig. 2), and has demonstrated the ability to treat patients with lumbar disc annular disease who have been unresponsive to conservative management $(29,33)$. A temperature-controlled thermal resistive coil provides conductive heating of the annulus in the temperature range that is thought to provide local denaturing of collagen fibrils, cauterize granulation tissue, and coagulate nerve fibers $(32,34,35)$. These therapeutic mechanisms take place without concomitant destabilization of the involved spinal motion segment(s) (36). IDET received US regulatory clearance in 1998 and currently carries a Category I CPT code. Notably, IDET is the only annuloplasty technique that has been accepted by the American Medical Association (AMA) CPT committee as meeting the scientific criteria to warrant its own specific CPT code.

There are 2 other minimally invasive catheterbased annuloplasty techniques currently in use at this time: percutaneous intradiscal radiofrequency thermocoagulation (PIRFT) and biacuplasty. Both of these methods use radiofrequency as an energy source. The PIRFT procedure employs the discTRODETM device (Radionics, Burlington, MA) has received US regulatory 


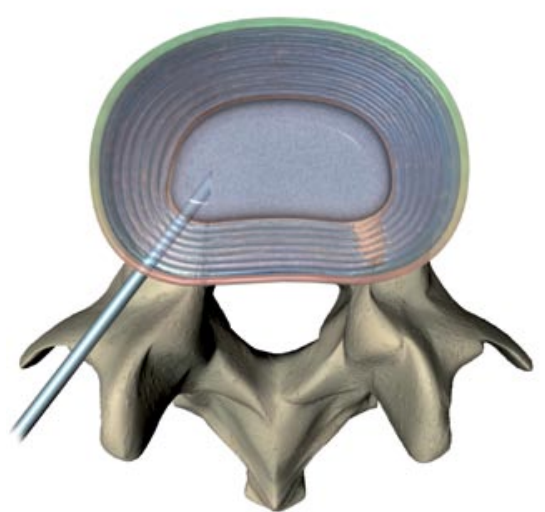

A. Following posterolateral puncture of the annulus, the introducer needle is positioned in the nucleus.

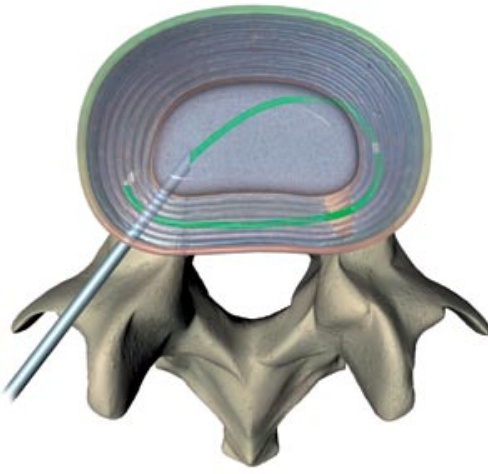

B. The IDET catheter is navigated circumferentially so that the heating element is positioned within the posterior annulus, across the previously identified tear.

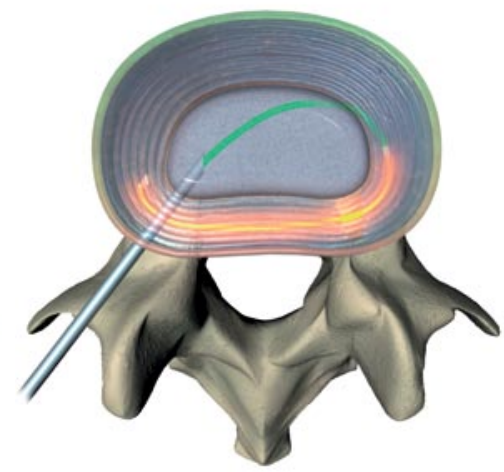

C. Finally, the heating protocol commences until $90^{\circ} \mathrm{C}$ is achieved for approximately 4 to 5 minutes.

Fig. 2. Temporal sequence of events during the IDET procedure.

clearance for a similar indication as IDET, but carries a Category III CPT code. This is a distinctly different intradiscal device consisting of a unipolar radiofrequency probe inserted into the annular/nuclear junction. Four clinical studies of this device have provided equivocal clinical results (37-40). Kapural et al (41) compared the outcomes among 21 IDET-treated patients and 21 matched cases treated with the discTRODE ${ }^{\mathrm{TM}}$. After 12 months of follow-up, the IDET-treated patients experienced significantly greater reductions in pain severity ( $81 \%$ vs. $33 \%, P=0.001$ ). Intradiscal biacuplasty (IDP) uses the Trans-Discal system (Baylis Medical, Montreal, (anada), a bipolar radiofrequency device, and has an equivalent regulatory and reimbursement status as PIRFT. Published clinical evidence is limited to one case report describing the results in a single patient and a prospective study of 15 patients with short-term follow-up $(42,43)$.

There have been 2 large, comprehensive reviews of the safety and effectiveness of IDET $(44,45)$. Appleby et al (45) conducted a quantitative meta-analysis using a random-effects model of the relative effectiveness of the IDET procedure based on the published findings from 17 peer-reviewed studies. The overall mean improvements were 2.9, 21.1, 18.0, and 7.0 units for pain severity (VAS), physical functioning (SF-36), bodily pain (SF-36), and Oswestry disability index, respectively. Average improvements in 3 of these 4 outcomes were substantially greater than the published minimal clinically important differences. Only the Oswestry findings, based on only 3 published studies, were slightly less than a 10 unit change, reported to be the minimal clinically important difference for this outcome. The overall incidence in complications estimated in this meta-analysis was $0.8 \%$.

Andersson et al (44) compared the clinical outcomes and complication rates between 18 IDET studies and 33 published studies of spinal fusion for treatment of discogenic pain. Overall, there were similar median percentage improvements realized after spinal fusion and the IDET procedure, respectively, for 2 of the 3 outcomes evaluated: pain severity (50\%, $51 \%)$, back function $(42 \%, 14 \%)$, and quality of life (46\%, 43\%). Perioperative complications were commonly associated with spinal fusion (median: 14\%, range: $2 \%$ to $54 \%, n=31$ study groups) whereas adverse events were rarely experienced with the IDET procedure (median: $0 \%$, range: $0 \%$ to $16 \%, n=14$ studies).

Thus, the typical improvement in back symptoms realized by IDET-treated patients exceeds the minimal clinically important difference of $30 \%$ for pain severity documented by Ostelo et al (46). The minimal clinically important difference represents the threshold amount of improvement that the patient perceives as clinically beneficial. 
Andersson et al (44) also reported that the median percentage of patients experiencing at least a 2 unit improvement in pain severity on a standard 10 $\mathrm{cm}$ VAS was $61 \%$ (range: $52 \%$ to $72 \%$ ) following IDET treatment. A 2 unit improvement represents the validated minimal clinically important difference in low back pain severity $(46,47)$.

The 2 randomized sham-controlled trials of the IDET procedure had conflicting findings $(48,49)$. Pauza et al (48) demonstrated significantly better improvement in pain severity ( $36 \%$ vs. $17 \%, P=0.045)$ and back function ( $35 \%$ vs. $12 \%, P<0.05$ ) among patients treated with the IDET procedure compared to patients randomly assigned to sham control. These improvements were realized in spite of a modest sample size and a notable placebo response among sham-treated patients. Alternatively, Freeman et al (49) reported an almost uniform lack of effectiveness in either treatment group on any outcome over 6 months.

Several observations are required regarding the study of Freeman and coworkers (49). First, as indicated above, this study failed to demonstrate either a treatment or a placebo response. These idiosyncratic results are particularly notable given the large body of evidence describing an identifiable placebo effect associated with sham procedures where the primary outcomes involve subjectivity, such as pain severity and its surrogates (50). It is likely that the method of patient selection may partially explain these findings. Specifically, many study subjects had markedly severe disc degeneration and a maximum duration of symptoms of up to 20 years. The IDET procedure is considered more appropriate in the sub-acute phase of injury with pain localized to the annulus and prior to the development of marked endplate or facet joint changes, as commonly occurs with advanced disc degeneration $(22,51)$. Lastly, each subject received a 100 mg intradiscal injection of cefazolin at the completion of the procedure, an amount well outside the norm. It has been demonstrated that short-term exposure to high doses of antibiotics (as low as $0.5-2.0 \mathrm{mg} / \mathrm{mL}$ ) can have a deleterious effect on the disc with respect to annular cell viability, proliferation, and metabolism (52). Studies have not extrapolated the effects of a super dose of antibiotics such as performed by Freeman and coworkers.

IDET is a minimally invasive percutaneous procedure that has been performed among thousands of patients worldwide since 1998 with few reported adverse effects. The procedure is relatively easy to perform for a trained interventionist and has the advantage of preserving the native disc structure (53). Consequently, undergoing the IDET procedure does not eliminate the possibility for surgery at a later time if severe symptoms persist or if disc degeneration progresses. However, if patients with definitive imaging and discographic evidence of internal disc disruption are selected properly, the IDET procedure may eliminate or delay for an extended period of time the need for extensive or aggressive spinal surgery.

\section{IDET Indications FOR UsE}

Internal disc disruption is characterized by degradation of the nucleus pulposus of the affected disc and disruption of the inner lamella of the annulus fibrosus by radial fissures $(1,54)$. Radial fissures correlate strongly with reproduction of the patient's pain by discography, and are independent of age and degenerative changes (55). There are no clinical examination tests by which internal disc disruption can be definitively distinguished from other causes of low back pain (23). Provocation discography is the only means of establishing the diagnosis $(10,23,56,57)$.

Magnetic resonance imaging (MRI), discography, and post-discography computed tomography (CT) scans are typically used to evaluate the source of discogenic low back pain. In particular, the loss of nuclear intensity on T2-weighted MRI images, intervertebral disc narrowing, annular fissures, and high-intensity zones may be suggestive of internal disc disruption (Fig. 3) $(7,8)$. However, relating this anatomy of annular disruption on imaging to the occurrence of low back pain, is difficult to establish. Provocation of concordant pain symptoms using low pressure discography, including one or more discordant discs as control, is needed to verify that specific discs with these degenerative characteristics are the pain generators (55). Furthermore, more detailed characteristics of the disc anatomy can be observed on x-ray images during the discography procedure, as well as on post-disc injection CT scan (Fig. 4) $(56,57)$. The results of these diagnostic procedures can be used to identify appropriate cases most likely to benefit from the IDET procedure. Fluoroscopic imaging of the correct IDET catheter placement is illustrated in Fig. 5.

Refined indications and contraindications for use for IDET are provided in Tables 1 and 2. Indications for use 


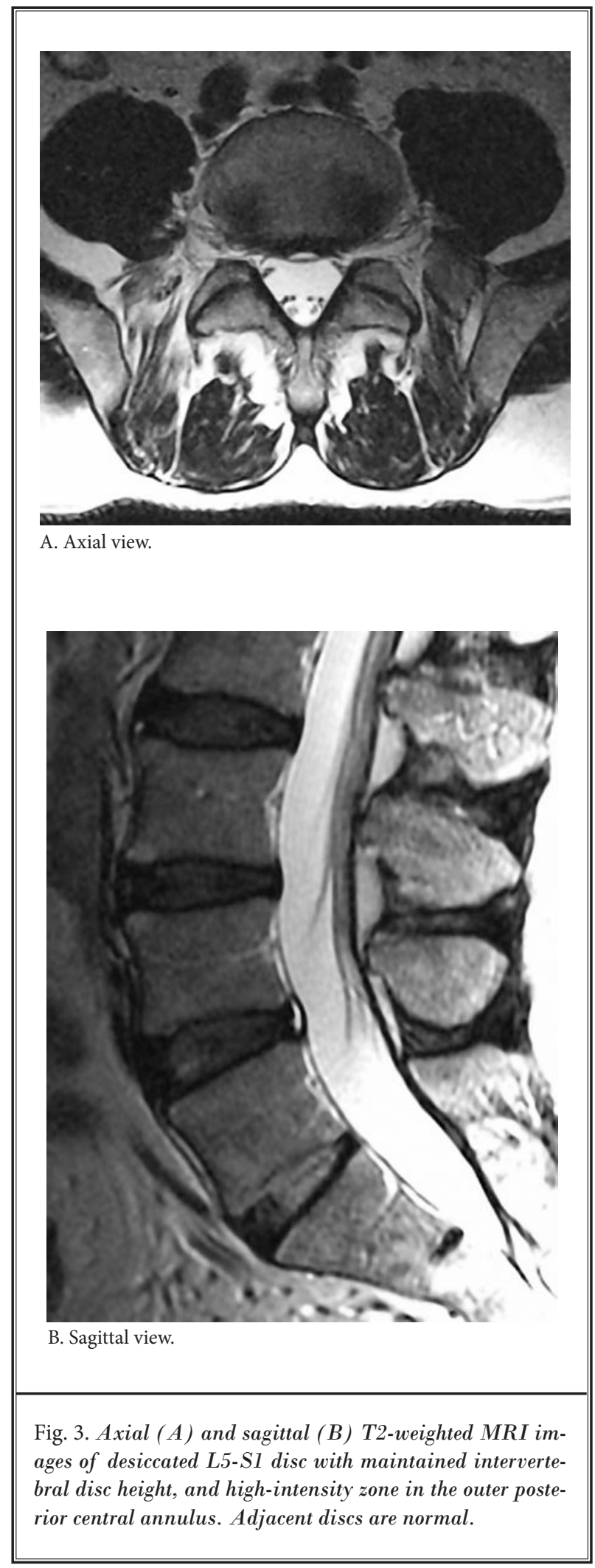

were developed from review of selection criteria from published clinical reports and review articles of IDET, and further refined by identifying components with the strongest positive predictive value and by direct physician feedback $(41,48,51,58-60)$. Final indications for use consist of both clinical and imaging criteria. Utilizing almost identical indications for use to select candidates for IDET treatment, Maurer et al (61) reported that in 56 patients followed for more than 20 months, 3 of 4 (75\%) experienced a clinically perceptible and beneficial improvement in back pain symptoms.

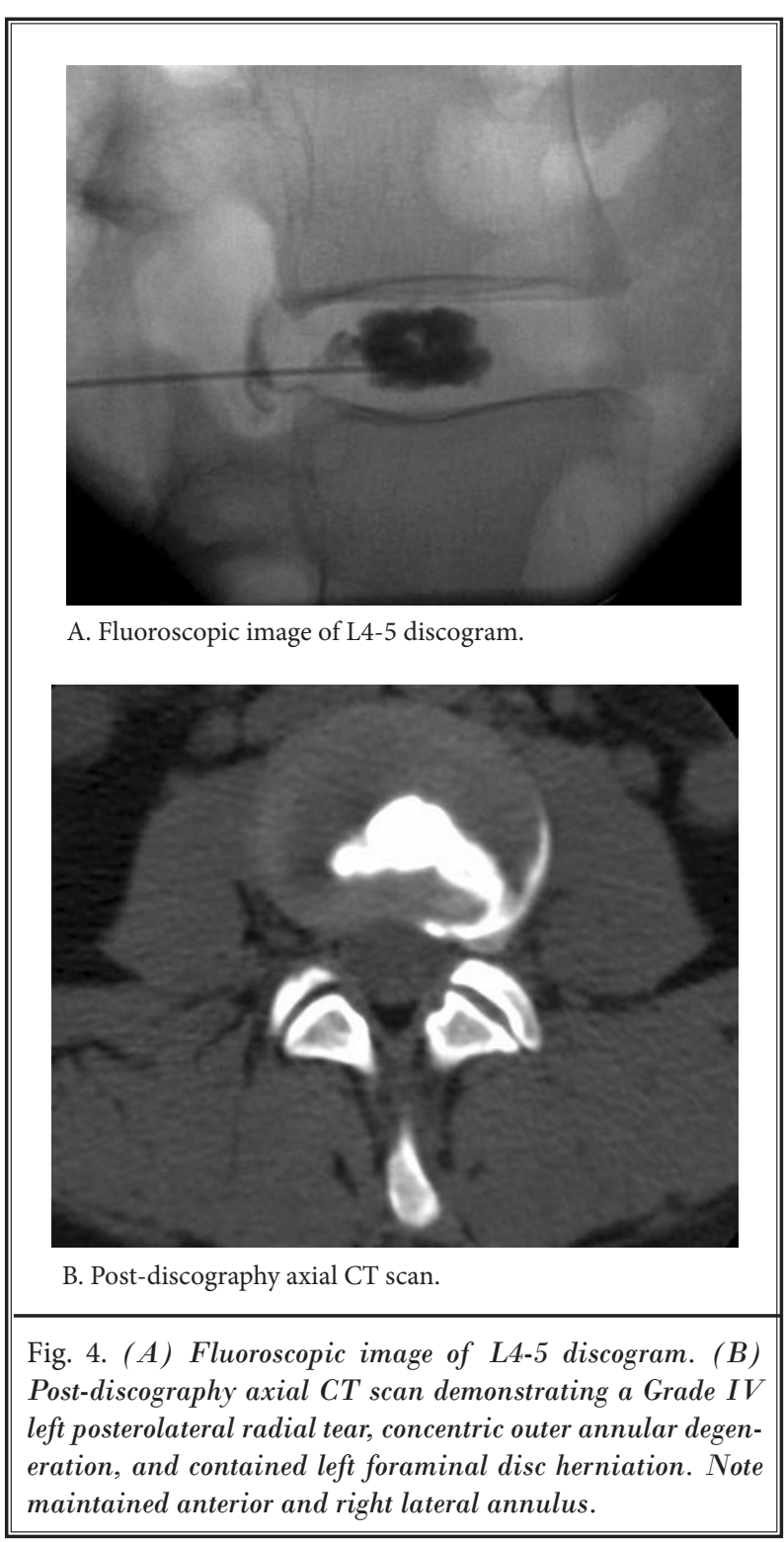




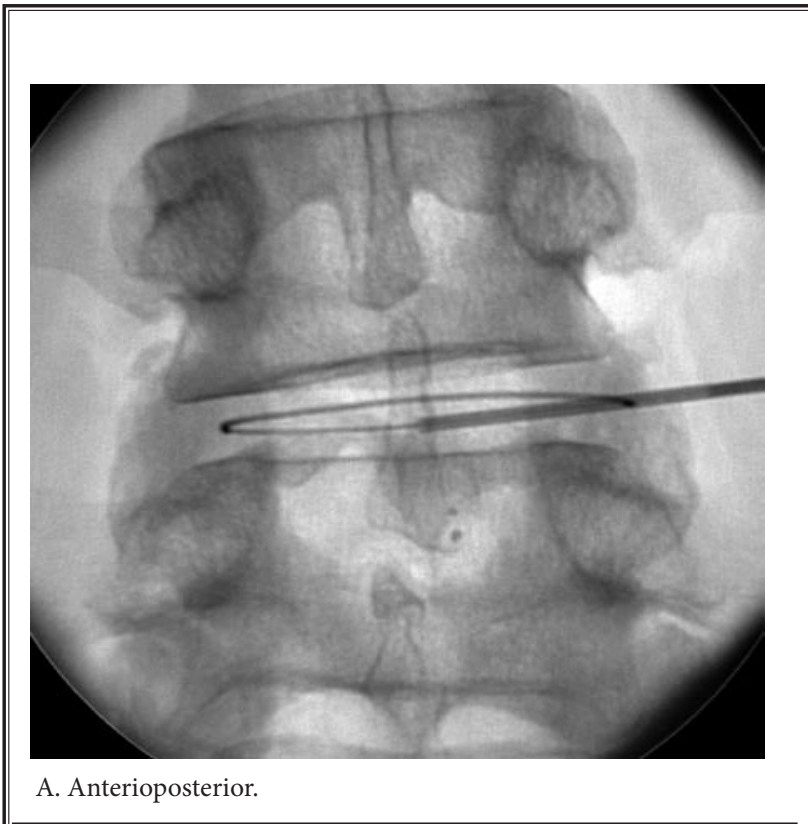

Fig. 5. Anteroposterior (A) and lateral (B) fluoroscopic images of the IDET catheter in proper position in the posterior and posterolateral annulus of the L4-5 intervertebral disc.

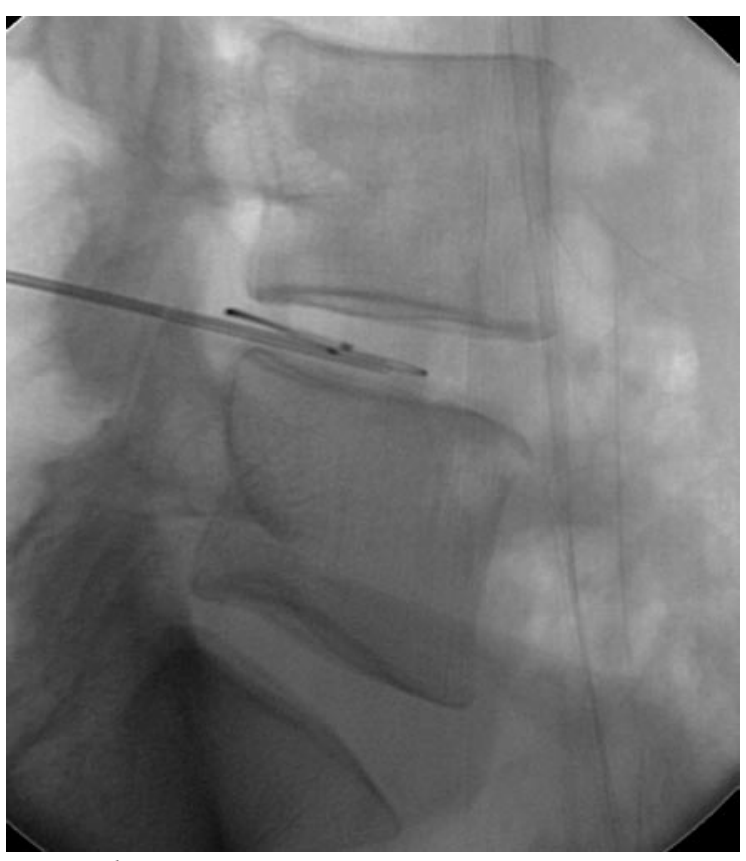

B. Lateral.

\section{Table 1. IDET Indications.}

1. Persistent symptoms of axial low back pain $+/$ - leg pain and impaired function $\geq 6$ months duration and nonresponsive to at least a 6 week course of conservative medical management.* Back pain $>$ leg pain.

2. History consistent with discogenic low back pain (e.g., pain reproduced on lumbar motion, significant functional limitation in sitting duration and tolerance) with normal lower extremity neurologic exam without marked motor deficit.

3. One to 3 desiccated discs with or without small, contained herniated nucleus pulposus evidenced by T2-weighted magnetic resonance imaging (MRI) that may exhibit a high intensity zone (HIZ). Involved disc(s) should have at least $50 \%$ remaining disc height.

4. Concordant pain provocation by low pressure ( $<50 \mathrm{psi}$ above opening pressure) discography at the affected level(s), without pain reproduction or with discordant pain at adjacent unaffected levels at up to 50 psi above opening pressure.

5. Posterior annular disruption such as radial and/or concentric fissure(s) to the outer annular fibers evidenced by computed tomography (CT) discogram.

* Nonsurgical management is the first line treatment modality and includes medication to reduce swelling or to relieve pain, epidural steroid injection, limits on physical activity, exercises and/or physical therapy, biopsychosocial rehabilitation, and a brace/corset for the lower back $(29,68,69)$.

\section{Previous IDET Technology Status}

For various reasons and based, in part, on the equivocal results of the single randomized controlled trial of Freeman and coworkers (49), several previous technology assessments failed to conclude that IDET was effective for the treatment of discogenic low back pain (62-65). However, these reviews generally gave less consideration to the large body of clinical evidence to the contrary from more than 20 published studies employing other designs as well as the favorable results demonstrated by Pauza and coworkers (48) in their randomized controlled trial study report. In contrast, in their practice guidelines, the In- 
Table 2: IDET Contraindications and Relative Contraindications.

\begin{tabular}{l}
\hline Contraindications \\
\hline 1. Severe disc degeneration at the affected lumbar level(s) as evidenced by $>50 \%$ disc height loss on plain anteroposterior (AP) and lateral \\
lumbar radiographs and/or MRI or CT. \\
2. Extruded or sequestered herniated nucleus pulposus at the affected level(s). \\
3. Previous lumbar back surgery (e.g., laminectomy, discectomy, or fusion) at the affected level(s). \\
4. IDET previously performed within the last 6 months at the same level. \\
5. Nerve root impingement and/or compression with chronic lower extremity radiculopathy causing new onset motor deficit. \\
6. Moderate to severe spinal stenosis (i.e., central, lateral, or foraminal) due to osteophyte and/or ligamentous overgrowth as evidenced by \\
7. MRI or CT, provided stenosis is the cause of pain. \\
8. Grade I spondylolisthesis with motion on flexion/extension radiographs or any translational instability at the affected level(s). \\
9. Grade II or greater spondylolisthesis. \\
10. Cervical degenerated disc(s). \\
11. Pregnancy. \\
12. Major psychological impairment. \\
\hline Relative Contraindications \\
1. Moderate spinal stenosis (i.e., central, lateral, or foraminal) due to soft disc bulging, protrusion, or herniation with claudication. \\
2. Grade I spondylolisthesis with no or minimal motion on flexion/extension radiographs. \\
3. Previous discectomy at the affected level(s). \\
4. Thoracic degenerated disc(s). \\
\hline \hline
\end{tabular}

ternational Spine Intervention Society (ISIS) lists IDET under its established procedures with similar patient selection criteria particularly regarding maintenance of disc height and lack of instability at the affected level(s) (66). Additionally, the American Society of Interventional Pain Physicians (ASIPP), utilizing a comprehensive, independent assessment methodology that evaluated the entire compendium of studies of IDET, concluded in their 2005 evidence-based practice guidelines in the management of chronic spinal pain that the evidence for IDET was strong for short-term relief and moderate for long-term relief in managing chronic discogenic low back pain (67). When this assessment was repeated in 2007 to account for additional publications, including that of Freeman and colleagues (49), the rating was revised to moderate for managing chronic discogenic low back pain (30). Most recently, the North American Spine Society (NASS) sponsored a special focus issue entitled Evidence-Informed Management of Chronic Low Back Pain Without Surgery summarizing the best available evidence on the safety and effectiveness of a number of interventions including IDET (32). This position statement concluded that "for patients with less functional impairment, relatively well-maintained disc heights, and discogenic pain caused by annular tears or protrusions less than 3 to $4 \mathrm{~mm}$, IDET or another lesser invasive procedure would seem to be a reasonable first option if the patient is unwilling to tolerate his or her pain and disability."

\section{Regulatory and Reimbursement Status}

The SpineCATH® Intradiscal Catheter (Smith \& Nephew, Memphis, TN) received 510(k) marketing clearance from the Food and Drug Administration (FDA) on February 4, 1998, "for the coagulation and decompression of disc material to treat symptomatic patients with annular disruption of contained herniated discs."

Currently, IDET is the only annuloplasty technique that is covered by a Category I CPT code. The coding designations are as follows: 
22526 Percutaneous intradiscal electrothermal annuloplasty, unilateral or bilateral including fluoroscopic guidance; single level

22527 One or more additional levels

C1754 SpineCATH Intradiscal catheter

\section{Conclusion}

Carefully selected patients with discogenic low back pain, nonresponsive to conservative care with definitive imaging and discographic evidence of internal disc disruption benefit clinically from IDET in terms of pain reduction and also functional and quality of life improvement. IDET offers a minimally invasive intermediate step in the continuum of care for these patients, with durable clinical improvement.

\section{Acknowledgmients}

These indications for use for IDET are endorsed by the American Society of Interventional Pain Physicians (ASIPP) (endorsement received 12 February 2008). This communication was supported, in part, by Smith \& Nephew (Memphis, TN).

\section{References}

1. Vernon-Roberts B, Moore RJ, Fraser RD. The natural history of age-related disc degeneration. The pathology and sequelae of tears. Spine 2007; 32:27972804.

2. Roberts S, Evans H, Trivedi J, Menage J. Histology and pathology of the human intervertebral disc. J Bone Joint Surg Am 2006; 88 Suppl 2:10-14.

3. Haefeli M, Kalberer F, Saegesser D, Nerlich AG, Boos N, Paesold G. The course of macroscopic degeneration in the human lumbar intervertebral disc. Spine 2006; 31:1522-1531.

4. Haid RW, Jr., Dickman CA. Instrumentation and fusion for discogenic disease of the lumbosacral spine. Neurosurg Clin N Am 1993; 4:135-148.

5. Adams MA, Freeman BJ, Morrison HP, Nelson IW, Dolan P. Mechanical initiation of intervertebral disc degeneration. Spine 2000; 25:1625-1636.

6. Lotz JC, Ulrich JA. Innervation, inflammation, and hypermobility may characterize pathologic disc degeneration: review of animal model data. J Bone Joint Surg Am 2006; 88 Suppl 2:76-82.

7. Peng B, Hou S, Wu W, Zhang C, Yang Y. The pathogenesis and clinical significance of a high-intensity zone (HIZ) of lumbar intervertebral disc on MR imaging in the patient with discogenic low back pain. Eur Spine J 2006; 15:583 587.

8. Griffith JF, Wang YX, Antonio GE, Choi KC, Yu A, Ahuja AT, Leung PC. Modified Pfirrmann grading system for lumbar intervertebral disc degeneration. Spine 2007; 32:E708-712.

9. Simpson EK, Parkinson IH, Manthey B, Fazzalari NL. Intervertebral disc disorganization is related to trabecular bone architecture in the lumbar spine. J Bone Miner Res 2001; 16:681-687.

10. Videman T, Nurminen M. The occurrence of anular tears and their relation to lifetime back pain history: A cadaveric study using barium sulfate discog. raphy. Spine 2004; 29:2668-2676.

11. Osti OL, Vernon-Roberts B, Fraser RD. 1990 Volvo Award in experimental studies. Anulus tears and intervertebral disc degeneration. An experimental study using an animal model. Spine 1990; 15:762-767.

12. Osti OL, Vernon-Roberts B, Moore R, Fraser RD. Annular tears and disc degeneration in the lumbar spine. A postmortem study of 135 discs. J Bone Joint Surg Br 1992; 74:678-682.
13. Ulrich JA, Liebenberg EC, Thuillier DU, Lotz JC. Repeated disc injury causes persistent inflammation. Spine 2007; 32:2812-2819.

14. Coppes MH, Marani E, Thomeer RT, Groen GJ. Innervation of "painful" lumbar discs. Spine 1997; 22:2342-2349.

15. Freemont AJ, Peacock TE, Goupille P, Hoyland JA, O’Brien J, Jayson MI. Nerve ingrowth into diseased intervertebral disc in chronic back pain. Lancet 1997; 350:178-181.

16. Johnson WE, Evans H, Menage J, Eisenstein SM, El Haj A, Roberts S. Immunohistochemical detection of Schwann cells in innervated and vascularized human intervertebral discs. Spine 2001; 26:2550-2557.

17. Inoue G, Ohtori S, Aoki Y, Ozawa T, Doya $\mathrm{H}$, Saito T, Ito T, Akazawa T, Moriya H, Takahashi K. Exposure of the nucleus pulposus to the outside of the anulus fibrosus induces nerve injury and regeneration of the afferent fibers innervating the lumbar intervertebral discs in rats. Spine 2006; 31:1433-1438.

18. Peng B, Hao J, Hou S, Wu W, Jiang D, Fu X, Yang Y. Possible pathogenesis of painful intervertebral disc degeneration. Spine 2006; 31:560-566. 
19. Peng B, Wu W, Hou S, Li P, Zhang C, Yang Y. The pathogenesis of discogenic low back pain. J Bone Joint Surg $\mathrm{Br}$ 2005; 87:62-67.

20. Weiler C, Nerlich AG, Bachmeier BE, Boos N. Expression and distribution of tumor necrosis factor alpha in human lumbar intervertebral discs: A study in surgical specimen and autopsy controls. Spine 2005; 30:44-53.

21. Burke JG, Watson RW, McCormack D, Dowling FE, Walsh MG, Fitzpatrick JM. Intervertebral discs which cause low back pain secrete high levels of proinflammatory mediators. I Bone Joint Surg Br 2002; 84:196-201.

22. Hurri H, Karppinen J. Discogenic pain. Pain 2004; 112:225-228.

23. Schwarzer AC, Aprill CN, Derby R, Fortin J, Kine G, Bogduk N. The prevalence and clinical features of internal disc disruption in patients with chronic low back pain. Spine 1995; 20:1878-1883.

24. Manchikanti L, Singh V, Pampati V, Damron KS, Barnhill RC, Beyer C, Cash KA. Evaluation of the relative contributions of various structures in chronic low back pain. Pain Physician 2001; 4:308-316.

25. Carey TS, Garrett JM, Jackman AM. Beyond the good prognosis. Examination of an inception cohort of patients with chronic low back pain. Spine 2000; 25:115-120.

26. Rhyne AL, Smith SE, Wood KE, Darden BV. Outcome of unoperated discogrampositive low back pain. Spine 1995; 20:1997-2000

27. Von Korff M. Studying the natural history of back pain. Spine 1994; 19:2041S$2046 \mathrm{~S}$

28. Turk DC. Understanding pain sufferers: The role of cognitive processes. Spine J 2004; 4:1-7.

29. Brodke DS, Ritter SM. Nonoperative management of low back pain and lumbar disc degeneration. J Bone Joint Surg Am 2004; 86-A:1810-1818.

30. Boswell MV, Trescot AM, Datta S, Schultz DM, Hansen HC, Abdi S, Sehgal N, Shah RV, Singh V, Benyamin RM, Patel VB, Buenaventura RM, Colson JD, Cordner HJ, Epter RS, Jasper JF, Dunbar EE, Atluri SL, Bowman RC, Deer TR, Swicegood JR, Staats PS, Smith HS, Burton AW, Kloth DS, Giordano J, Manchikanti L. Interventional techniques: Evidencebased practice guidelines in the man- agement of chronic spinal pain. Pain Physician 2007; 10:7-111.

31. Deyo RA. Back surgery--who needs it? N Engl J Med 2007; 356:2239-2243.

32. Derby R, Baker RM, Lee $\mathrm{CH}$, Anderson $P A$. Evidence-informed management of chronic low back pain with intradiscal electrothermal therapy. Spine / 2008; 8:80-95.

33. Bridwell KH, Anderson PA, Boden SD, Vaccaro AR, Zigler JE. What's new in spine surgery. I Bone Joint Surg Am 2004; 86-A:1587-1596.

34. Shah RV, Lutz GE, Lee J, Doty SB, Rodeo S. Intradiskal electrothermal therapy: a preliminary histologic study. Arch Phys Med Rehabil 2001; 82:1230-1237.

35. Bono CM, Iki K, Jalota A, Dawson K, Garfin SR. Temperatures within the lumbar disc and endplates during intradiscal electrothermal therapy: Formulation of a predictive temperature map in relation to distance from the catheter. Spine 2004; 29:1124-1129.

36. Lee J, Lutz GE, Campbell D, Rodeo SA, Wright T. Stability of the lumbar spine after intradiscal electrothermal therapy. Arch Phys Med Rehabil 2001; 82:120122.

37. Barendse GA, van Den Berg SG, Kessels $A H$, Weber WE, van Kleef M. Randomized controlled trial of percutaneous intradiscal radiofrequency thermocoagulation for chronic discogenic back pain: Lack of effect from a 9o-second $70 \mathrm{Cle}$ sion. Spine 2001; 26:287-292.

38. Ercelen O, Bulutcu E, Oktenoglu T, Sasani M, Bozkus H, Cetin Saryoglu A, Ozer F. Radiofrequency lesioning using two different time modalities for the treatment of lumbar discogenic pain: A randomized trial. Spine 2003; 28:19221927.

39. van Kleef $M$, Barendse GA, Wilmink JT. Percutaneous intradiscal radio-frequency thermocoagulation in chronic non-specific low back pain. Pain Clinic 1996; 9:259-268.

40. Finch PM, Price LM, Drummond PD. Radiofrequency heating of painful annular disruptions: One-year outcomes. J Spinal Disord Tech 2005; 18:6-13.

41. Kapural L, Hayek S, Malak O, Arrigain S, Mekhail N. Intradiscal thermal annuloplasty versus intradiscal radiofrequency ablation for the treatment of discogenic pain: A prospective matched control trial. Pain Med 2005; 6:425-431.
42. Kapural L, Mekhail N. Novel intradiscal biacuplasty (IDB) for the treatment of lumbar discogenic pain. Pain Pract 2007; 7:130-134.

43. Kapural L, Ng A, Dalton J, Mascha E, Kapural M, de la Garza M, Mekhail N. Intervertebral disc biacuplasty for the treatment of lumbar discogenic pain: Results of a six-month follow-up. Pain Med 2008; 9:60-67.

44. Andersson GB, Mekhail NA, Block JE. Treatment of intractable discogenic low back pain. A systematic review of spinal fusion and intradiscal electrothermal therapy (IDET). Pain Physician 2006; 9:237-248.

45. Appleby D, Andersson G, Totta M. Meta-analysis of the efficacy and safety of intradiscal electrothermal therapy (IDET). Pain Med 2006; 7:308-316.

46. Ostelo RW, Deyo RA, Stratford P, Waddell G, Croft P, Von Korff M, Bouter LM, de Vet HC. Interpreting change scores for pain and functional status in low back pain. Towards international consensus regarding minimal important change. Spine 2008; 33:90-94.

47. Hagg O, Fritzell P, Nordwall A. The clinical importance of changes in outcome scores after treatment for chronic low back pain. Eur Spine J 2003; 12:12-20.

48. Pauza KJ, Howell S, Dreyfuss P, Peloza JH, Dawson K, Bogduk N. A randomized, placebo-controlled trial of intradiscal electrothermal therapy for the treatment of discogenic low back pain. Spine J 2004; 4:27-35.

49. Freeman BJ, Fraser RD, Cain CM, Hall DJ, Chapple DC. A randomized, doubleblind, controlled trial:Intradiscal electrothermal therapy versus placebo for the treatment of chronic discogenic low back pain. Spine 2005; 30:2369-2377.

50. Turner JA, Deyo RA, Loeser JD, Von Korff $M$, Fordyce WE. The importance of placebo effects in pain treatment and research. JAMA 1994; 271:1609-1614.

51. Kapural L, Mekhail N, Korunda Z, Basali A. Intradiscal thermal annuloplasty for the treatment of lumbar discogenic pain in patients with multilevel degenerative disc disease. Anesth Analg 2004; 99:472-476.

52. Hoelscher GL, Gruber HE, Coldham G, Grigsby JH, Hanley EN, Jr. Effects of very high antibiotic concentrations on human intervertebral disc cell proliferation, viability, and metabolism in vitro. 
Spine 2000; 25:1871-1877.

53. Mochida J, Nishimura K, Nomura T, Toh $\mathrm{E}$, Chiba M. The importance of preserving disc structure in surgical approaches to lumbar disc herniation. Spine 1996; 21:1556-1563.

54. Bogduk N. The lumbar disc and low back pain. Neurosurg Clin N Am 1991; 2:791-806.

55. Moneta GB, Videman T, Kaivanto K, Aprill C, Spivey M, Vanharanta $H$, Sachs BL, Guyer RD, Hochschuler SH, Raschbaum RF, et al. Reported pain during lumbar discography as a function of anular ruptures and disc degeneration. A re-analysis of 833 discograms. Spine 1994; 19:1968-1974.

56. Guyer RD, Ohnmeiss DD. Lumbar discography. Spine J 2003; 3:11S-27S.

57. Fritz J, Niemeyer T, Clasen S, Wiskirchen J, Tepe G, Kastler B, Nagele T, Konig CW, Claussen CD, Pereira PL. Management of chronic low back pain: Rationales, principles, and targets of imaging-guided spinal injections. Radiographics 2007; 27:1751-1771.

58. Lee MS, Cooper G, Lutz GE, Lutz C, Hong HM. Intradiscal electrothermal therapy (IDET) for treatment of chronic lumbar discogenic pain: A minimum 2Year clinical outcome study. Pain Physician 2003; 6:443-448.
59. Mekhail N, Kapural L. Intradiscal thermal annuloplasty for discogenic pain: An outcome study. Pain Practice 2004; 4:84-90.

6o. Bryce DA, Nelson J, Glurich I, Berg RL. Intradiscal electrothermal annuloplasty therapy: a case series study leading to new considerations. WMJ 2005; 104:39-46.

61. Maurer P, Block JE, Squillante D. Intradiscal electrothermal therapy (IDET) provides effective symptom relief in patients with discogenic low back pain. J Spinal Disord Tech 2008; 21:55-62.

62. Freeman BJ. IDET: a critical appraisal of the evidence. Eur Spine J 2006; 15 Suppl 3:S448-457.

63. Gibson JN, Waddell G. Surgery for degenerative lumbar spondylosis: Updated Cochrane Review. Spine 2005; 30:2312-2320.

64. Urrutia G, Kovacs F, Nishishinya MB, Olabe J. Percutaneous thermocoagulation intradiscal techniques for discogenic low back pain. Spine 2007; 32:1146-1154.

65. Airaksinen O, Brox J, Cedraschi C, Hildebrandt J, Klaber-Moffett J, Kovacs F, Mannion AF, Reis S, Staal JB, Ursin H, Zanoli G. Chapter 4. European guidelines for the management of chronic nonspecific low back pain. Eur Spine J 2006; 15 Suppl 2:S192-300.

66. Intradiscal electrothermal therapy. In: Bogduk N, ed. Practice guidelines for spinal diagnostic and treatment procedures. First ed. International Spine Intervention Society, San Francisco, 2004:219-236.

67. Boswell MV, Shah RV, Everett CR, Sehgal N, Brown AM, Abdi S, Bowman RC, 2nd, Deer TR, Datta S, Colson JD, Spillane WF, Smith HS, Lucas LF, Burton AW, Chopra P, Staats PS, Wasserman RA, Manchikanti L. Interventional techniques in the management of chronic spinal pain: evidence-based practice guidelines. Pain Physician 2005; 8:147.

68. Guzman J, Esmail R, Karjalainen K, Malmivaara A, Irvin E, Bombardier C. Multidisciplinary rehabilitation for chronic low back pain: Systematic review. BMJ 2001; 322:1511-1516.

69. van Tulder $M$, Becker $A$, Bekkering $T$, Breen A, del Real MT, Hutchinson A, Koes B, Laerum E, Malmivaara A. Chapter 3. European guidelines for the management of acute nonspecific low back pain in primary care. Eur Spine J 2006; 15 Suppl 2:S169-191. 